\title{
Stereotactic Body Radiation Therapy (SBRT) in Hepatocellular Carcinoma
}

\author{
Horatio R. Thomas ${ }^{1} \cdot$ Mary Feng ${ }^{1}$ \\ Accepted: 20 December 2020 / Published online: 14 January 2021 \\ (C) The Author(s) 2021
}

\begin{abstract}
Purpose of Review Hepatocellular carcinoma (HCC) is a rising cause of mortality and morbidity, and although surgical resection is the preferred curative local therapy, $<30 \%$ of patients are candidates at diagnosis. This review discusses SBRT as an option in a variety of clinical scenarios.

Recent Findings Multiple retrospective and prospective studies demonstrate that stereotactic body radiation therapy (SBRT) is an effective bridge for transplant candidates and local therapy for patients with inoperable early-, intermediate-, or advanced-stage disease. SBRT is associated with excellent local control, and it is well-tolerated despite study cohorts enriched with patients who failed prior therapies and had poor baseline liver function.

Summary Additional randomized control trials are needed to determine the ideal treatment regimen and patient selection for SBRT.
\end{abstract}

Keywords $\mathrm{HCC}$ treatment $\cdot \mathrm{HCC}$ radiation $\cdot \mathrm{HCC}$ SBRT $\cdot \mathrm{HCC}$ radiation

\section{Introduction}

Hepatocellular carcinoma (HCC) is the most common primary liver cancer ( $75-85 \%$ of liver cancers), the fifth most common cancer worldwide, and the third leading cause of cancer mortality $[1,2]$. The incidence of HCC is driven by disparate risk factors in different parts of the world. As a result, HCC has increased in frequency in Europe and the USA while remaining stable in east Asian countries over the past few decades [3-6]. Chronic infection with hepatitis $B$ and $C$ viruses are major risk factors in Asia while chronic heavy alcohol use, obesity, and diabetes are the major drivers in the USA and Europe. Other risk factors include hemochromatosis, alpha-1antitrypsin deficiency, and exposure to aflatoxin and mycotoxin in food [7]. Despite advances in screening for and diagnosis of HCC at earlier stages, management remains challenging.

This article is part of the Topical Collection on Hepatic Cancer

Mary Feng

mary.feng@ucsf.edu

1 Department of Radiation Oncology, University of California San Francisco, San Francisco, CA, USA
Disease staging guides the treatment of HCC. While over 18 staging systems have been developed for the categorization of HCC, Barcelona Clinic Liver Cancer (BCLC) is the most widely adopted system for management [8-12]. The BCLC system classifies HCC into 5 prognostic categories (very early, early, intermediate, advanced stage, terminal stage) based on tumor size, tumor burden, liver function based on ChildPugh (CP) score, and performance status [10]. Patients with very early- and early-stage disease are preferentially treated with surgical resection, transplantation, and/or ablation. Surgical resection remains the primary curative treatment $[13,14]$. Up to $75-80 \%$ of the liver can be safely resected in non-cirrhotic patients, and surgery has been shown to improve overall survival [15]. Intermediate-stage disease has historically been managed with chemoembolization, while advanced or terminal disease is generally treated with systemic therapy.

Despite improved radiographic screening and follow-up, $\leq$ $30 \%$ of patients are diagnosed with very early- or early-stage disease in the USA, and less than $5 \%$ of patients are good surgical candidates due to poor liver function, age, and/or other comorbidities $[16,17]$. While patients with early-stage disease and poor liver function may be treated with orthotopic liver transplantation, patients often face long waitlists $[18,19]$. Consequently, most patients with liver-confined $\mathrm{HCC}$ receive local therapies to achieve maximal tumor control while 
preserving liver function. In the absence of surgical options, aggressive local therapy options including ablation therapies (e.g., radiofrequency (RFA), percutaneous laser (PLA), microwave (PVA), or cryo (CrA)) and arterial embolization techniques (e.g., transarterial chemoembolization (TACE) and transarterial embolization (TAE)) have historically played a large role in HCC management [20-23]. Recently, radiation therapy has been increasingly used for the management of HCC in patients who previously failed or are not candidates for surgery, ablation, and/or embolization. Stereotactic body radiation therapy (SBRT), in particular, promises precise, noninvasive, aggressive local therapy for HCC. Herein, we review the literature on the evolving use of SBRT to treat patients with HCC with an emphasis on patient selection, treatment, clinical outcomes, and associated toxicity.

\section{Bridge to Transplantation}

Orthotopic liver transplantation is an alternative to definitive surgical resection for patients who meet the Milan Criteria (single tumor $\leq 5 \mathrm{~cm}$ or $\leq 3$ nodules that are each $\leq 3 \mathrm{~cm}$ ) but are ineligible for surgery due to impaired liver function [24]. This approach has the benefit of treating both hepatocellular carcinoma and comorbid liver disease. However, up to 20 $30 \%$ of patients with HCC who are initially eligible for transplantation experience significant disease progression that invalidates their candidacy while awaiting the procedure $[25$, 26]. Local therapies such as RFA, TACE, and SBRT may offer these patients effective local control as a bridge to transplantation $[27,28]$.

Several studies have shown that patients who receive radiation therapy as a bridge to transplant achieved a $>70-100 \%$ radiographic LC and OS over a 5- to 8-month period [27, 29-33]. An early prospective series of 10 patients showed that conformal radiation therapy is an effective strategy for bridging to transplant [31]. Half of the patients received CRT after ineffective local control from previous treatment with RFA or TACE while the other half received CRT alone due to unsuitability for TACE or RFA based on tumor size or location. Ineligibility for RFA and TACE included thrombocytopenia, arterial occlusion, tumor multifocality, and necrosis of the biliary tree. All patients experienced a significant reduction in AFP and in-field tumor control with a median time to transplantation of 157 days after RT. Seven patients experienced partial radiographic response, an additional 2 achieving stable disease, and the final patient received a transplant after 1 fraction of treatment. Although CRT was well-tolerated in this report of select patients with mostly CP A and B liver disease, a similar volume of the treated liver has been associated with $\sim 30 \%$ grade 3 or 4 toxicities in other series $[22,34,35]$.

Subsequent studies explored the technique of SBRT as a method of limiting the volume of the liver treated while also dose-escalating to intensify treatment, improving both effectiveness and safety. In a retrospective review of 10 patients that received SBRT using Cyberknife to $11 \mathrm{HCC}$ that were up to $5.5 \mathrm{~cm}$ and ultimately underwent transplantation ( median time of 151 days), all experienced a pathologic partial response with 3 fractions of treatment [30]. The cohort had an OS and DFS of $100 \%$ at 5 years with four patients experiencing mild toxicity including nausea, fatigue, or abdominal pain. A retrospective analysis summarizing the Memorial Sloan Kettering experience with SBRT bridge to orthotopic liver transplant showed a 3-year OS and DFS of $77 \%$ and $74 \%$ with a pathological response rate of $68 \%$ [32]. In this study, radiological response correlated poorly with pathological outcomes, and treatment failure due to recurrence was significantly associated with tumor size. Notably, $29 \%$ of patients experienced a worsening CP score before transplantation in a cohort where all patients had a CP-B7 or better. A larger phase I/II study from the University of Indiana further clarified the efficacy and tolerability of SBRT as a bridge to transplantation [36]. Twenty-three of the 60-patient cohort receiving SBRT for $\mathrm{HCC}$ were candidates for transplant. Ultimately, all candidates underwent transplantation and achieved 2 years of PFS and OS rate of $69 \%$ and $96 \%$, respectively. Durable local control was achieved before and after transplant, as patients with progressive disease developed extrahepatic lesions. While SBRT in the total cohort was welltolerated, $35 \%$ of patients developed grade 3 hematologic or hepatic toxicity. Notably, about $81 \%$ of patients who developed grade 3 toxicity had baseline grade 2 toxicity, and adverse toxicity was associated with worse underlying pretreatment liver function. Currently, SBRT treatments can be adjusted based on liver function to achieve the optimal balance for each patient.

\section{How Does SBRT Compare with Other Local Therapy Modalities in Bridging Patients to Transplantation?}

Princess Margaret Hospital conducted a respective review of 406 patients who received bridging therapies, 36 of which received SBRT while 99 patients received TACE, and 244 patients received RFA [37•]. Notably, patients treated with SBRT after failing RFA or TACE were placed in the SBRT group for analysis. The study showed no difference in the rates of transplantation completion (80 to $83 \%$ ), transfusion requirement (median 2 units of packed RBCs), postoperative length of stay (10 days), or post-transplant 5-year overall survival $(56-61 \%)$ between the three modalities. However, the pathological response of explanted tumors was lower with SBRT (13\%) compared with RFA (49\%) and TACE (24\%). Multiple hypotheses have been posited for the lower rate of pathological response including variable time between bridge treatment and transplantation and delayed pathological response to tumors in response to RT. Also, patients were treated with a lower biologically effective dose than reported in 
other studies. Despite the lower pathological response, the equivalent rate of transplant completion and peri-operative morbidity and mortality demonstrates that SBRT does not complicate surgery or worsen post-transplant outcomes.

These data demonstrate that SBRT is a safe and effective modality for preventing tumor progression in patients with HCC who are transplant candidates [32, 36, 38, 39]. Notably, SBRT cohorts performed well despite their enrichment with patients with poor liver function, challenging tumor location, larger tumor size, and failed local treatment. Most patients experienced minimal toxicity, though reported grade $\geq 3$ toxicity rates range from 0 to $\sim 35 \%[36,39-41]$. Compared with RFA and TACE, SBRT has been associated with equivalent or lower toxicity or hospitalization [37•, 42]. SBRT has been associated with worse liver function, though it is likely that patients with lower liver function reserve are treated SBRT since they no longer qualify for intra-arterial therapies. Despite multiple studies demonstrating the safety or efficacy of SBRT in preventing progression, there is limited specific data on the utility of downstaging patients [43], although it has been done. The delayed pathological response in prior series suggests that downstaging may take months to achieve, so that treating while a patient is still within transplant criteria may be a more effective strategy than downstaging.

While many of the retrospective cohorts used SBRT for patients who either were not candidates for or had failed other local therapy options, the prospective data suggest that SBRT may be a reasonable first-line option for bridging to transplantation. Additional prospective data are needed to clarify relative efficacy, toxicity, and surgical implications of SBRT compared with RFA and TACE. Historically, it has been challenging to compare the three modalities in a randomized trial. An ongoing clinical trial comparing TACE to SBRT at Lahey Clinic (Burlington, MA) as a bridge to transplant in patients with HCC may further clarify this question (NCT02182687).

\section{Early-Stage Inoperable HCC}

Patients with BCLC stage-A HCC have small $(\leq 3 \mathrm{~cm})$ tumors, limited tumor burden ( $\leq 3$ foci), and normal to moderately compromised liver function (CP A or B) [10]. Many of these patients are ineligible for primary surgical resection or transplantation due to age and comorbidities. Curative options include aggressive local ablation therapies. RFA is the most commonly used ablation therapy modality and has the most accumulated evidence of its efficacy in treating HCC. Multiple randomized trials summarized in a recent Cochrane meta-analysis have demonstrated that treatment of $\mathrm{HCC}$ with RFA is associated with improved overall survival compared with treatment with percutaneous ethanol injection (PEI) [44]. However, RFA is not appropriate for lesions adjacent to large vessels (e.g., portal vein and hepatic artery branches), central biliary structures, stomach, bowel, or heart. Also, the efficacy of RFA decreases with tumor size. SBRT does not have these treatment limitations and may be an effective modality for these patients.

SBRT has gradually gained popularity for treating patients with early-stage HCC who are not candidates for ablation therapy or failed primary ablation. In 2009 , Romeo et al. reported a phase I/II study demonstrating the efficacy of SBRT as the primary treatment for eight patients with unresectable localized HCC who had not received other interventions. Patients with 1-2 lesions, $\leq 7 \mathrm{~cm}$ (total), KPS $>80 \%$, and $\mathrm{CP} \mathrm{A}$ or B were treated in 3 or 5 sessions and achieved a 2year local control rate of $82 \%$ [45]. While most patients tolerated treatment well, 1 patient with CP B liver function developed acute grade 5 liver failure. Overall, it demonstrated that SBRT may be effective primary local therapy in select patients. A recent larger phase I/II trial at the University of Indiana evaluated the efficacy SBRT for 59 patients with untreated HCC, $\leq 5$ lesions ( $84 \%$ had 1 lesion), CP A or B, and ECOG 0-1 [46]. Primary treatment with SBRT achieved a response rate and $3 \mathrm{y}-\mathrm{LC}$ in $\sim 90 \%$ of patients. Better baseline liver function was associated with higher post-SBRT survival. CP A and B patients had a PFS of 22.3 months and 10 months and a median overall survival of 44.4 months and 17.0 months, respectively. Additional prospective trials further corroborate the efficacy of SBRT in achieving 80-100\% 2-year local control in patients with localized HCC (Table 1).

Additional studies have demonstrated that SBRT has a comparable or better efficacy compared with RFA or TACE. The University of Michigan reported a single-institution retrospective study of 224 patients with inoperable localized HCC treated with RFA ( $\sim 70 \%$ of cohort) or SBRT $(30 \%)$ $[54,55]$. The SBRT and RFA groups included a similar number of lesions treated and tumor sizes, and they demonstrated comparable 2-year LC rates $(\sim 80 \%)$ and overall survival at 1 year $(\sim 70 \%)$ and 2 years $(\sim 50 \%)$. Despite the enrichment with patients' adverse features in the SBRT (e.g., failed prior treatment, lower baseline liver function, higher AFP), it was associated with high 1-year LC rates $(97.4 . \%$ vs. $83.6 \%)$. In addition, RFA was associated with worse local control for larger tumors $(\geq 2 \mathrm{~cm})$ compared with SBRT. These results suggest that SBRT is a good initial treatment option for patients with localized HCC.

SBRT achieves high rates of local control for localized HCC with reasonable toxicity $[46,50,53]$. Severe toxicity (grade $\geq 3$ ) in recent reports ranged from 5 to $38 \%$ [46, 50, $52,55-57]$, generally decreasing over time as experience with SBRT grows. The most commonly reported severe toxicities include worsening hematologic function and hepatic dysfunction. Less commonly patients experience severe nausea and fatigue. In addition to experience, the difference in the report rate of toxicity may result from institutional differences in patient selection, inherent differences in the sensitivity of the treated liver region to radiation, and dose-escalation and 
Table 1 Prospective phase I and II trials of SBRT for HCC with $>20$ patients

\begin{tabular}{|c|c|c|c|c|c|c|c|}
\hline Study & $n$ & $\begin{array}{l}\text { CP score/BCLC } \\
\text { Stage }\end{array}$ & $\begin{array}{l}\text { Prior } \\
\text { treatment }\end{array}$ & $\begin{array}{l}\text { Tumor size } \\
\text { (range) }\end{array}$ & $\begin{array}{l}\text { Number of } \\
\text { lesions }\end{array}$ & Outcomes & $\begin{array}{l}\text { Grade } \geq 3 \\
\text { toxicity }\end{array}$ \\
\hline Tse $(2008) *[47]$ & 31 & $\begin{array}{l}\text { CP A } \\
\text { BCLC A-C }\end{array}$ & $\begin{array}{l}\text { TACE } 6 \% \\
\text { RFA } 13 \% \\
\text { Other } 61 \%\end{array}$ & $173 \mathrm{cc}(9-1913)$ & $\leq 3$ & $\begin{array}{l}1 \mathrm{y}-\mathrm{LC} 65 \% \\
1 \mathrm{y}-\mathrm{OS} 48 \%\end{array}$ & $26 \%$ \\
\hline Kang (2012) [48] & 42 & $\begin{array}{l}\text { CP A-B } \\
\text { BCLC A-C }\end{array}$ & TACE $100 \%$ & $2.9 \mathrm{~cm}(1-8)$ & NR & $\begin{array}{l}2 y-L C 95 \% \\
2 y-P F S 34 \% \\
2 y-O S 69 \%\end{array}$ & $15 \%$ \\
\hline Bujold (2013) [49] & 102 & $\begin{array}{l}\text { CP A } \\
\text { BCLC A-C }\end{array}$ & $\begin{array}{l}\text { TACE 22\% } \\
\text { RFA 34\% } \\
\text { Surgery } 9 \%\end{array}$ & $7.2 \mathrm{~cm}(1.4-23.1)$ & NR & $\begin{array}{l}\text { 1y-LC } 97 \% \\
\text { med-OS } 17 \\
\text { mo }\end{array}$ & $25 \%$ \\
\hline Lasley (2015) [46] & 59 & $\begin{array}{l}\text { CP A-B } \\
\text { BCLC NR }\end{array}$ & NR $15 \%$ & 33.6 cc $(2-107)$ & NR & $\begin{array}{l}C P-A \\
3-y \text { LC } 91 \% \\
3 y-P F S 48 \% \\
3 y-O S 61 \% \\
C P-B \\
3 y-L C 82 \% \\
3 y-P F S 23 \% \\
3 y-O S 26 \%\end{array}$ & $\begin{array}{l}\text { CP A: } 10 \% \\
\text { CP B: } 38 \%\end{array}$ \\
\hline Takeda (2016) [50] & 90 & $\begin{array}{l}\text { CP A-B } \\
\text { BCLC 0-C }\end{array}$ & $\begin{array}{l}\text { TACE 28\% } \\
\text { RFA 3\% } \\
\text { Other: } 17 \%\end{array}$ & $2.3 \mathrm{~cm}(1.0-4)$ & NR & $\begin{array}{l}3 y-\operatorname{LC} 96.3 \% \\
3 y-O S 66.7 \%\end{array}$ & $11 \%$ \\
\hline Feng $(2018)^{*}[51]$ & 69 & $\begin{array}{l}\text { CP A-B } \\
\text { BCLC NR }\end{array}$ & $\mathrm{NR}$ & $3 \mathrm{~cm}(0-13)$ & NR & $\begin{array}{l}2 \mathrm{y}-\mathrm{LC} 95 \% \\
2 \mathrm{y}-\mathrm{OS} 28 \%\end{array}$ & $3 \%$ \\
\hline Jang (2019) [52] & 74 & $\begin{array}{l}\text { CP A-B } \\
\text { BCLC 0-C }\end{array}$ & TACE $57 \%$ & $2.4 \mathrm{~cm}(1.0-9.9)$ & $\leq 2$ & $\begin{array}{l}3 y-L C \text { 95\% } \\
3 y-P F S 36 \% \\
3 y-O S 76 \%\end{array}$ & $3 \%$ \\
\hline $\begin{array}{l}\text { Durand-Labrunie (2020) } \\
\text { [53] }\end{array}$ & 44 & $\begin{array}{l}\text { CP A-B } \\
\text { BCLC 0-A }\end{array}$ & None & $2.8 \mathrm{~cm}(1.0-6.0)$ & 1 & $\begin{array}{l}1.5 \mathrm{y}-\mathrm{LC} 98 \% \\
1.5 \mathrm{y}-\mathrm{OS} 72 \%\end{array}$ & $31 \%$ \\
\hline
\end{tabular}

*Published study of SBRT with primary hepatocellular carcinomas and other tumors in the liver. Reported values are specifically for patients who received SBRT for $\mathrm{HCC}$

$B C L C$ Barcelona Clinic Liver Cancer, $C P$ Child-Pugh, $L C$ local control, $N R$ not reported, $O S$ overall survival, $R F A$ radiofrequency ablation, $P F S$ progression-free survival, TACE transarterial chemoembolization

fractionation. Notably, the population of patients receiving SBRT is usually enriched with patients with poor baseline liver function. The University of Indiana's prospective trial reported that severe toxicity was lower in patients with baseline CP A compared with CP B (11\% vs. 38\%) [46]. Other studies have reported high rates of toxicity in patients with $\mathrm{CP}$ $\mathrm{B}$ disease, and these patients should be treated with caution by experienced centers [58].

Further studies are needed to elucidate appropriate patient selection and dose and fractionation for SBRT, with particular attention to dose limits to the normal liver that minimize toxicity. Radiation treatments are already highly customized for patients based on a combination of metrics including mean dose to the liver and methods of preserving liver function as much as possible, but there is still much work to be done. These studies may further clarify which risk factors predispose these patients to grade three toxicity. In addition, prospective studies comparing SBRT to RFA would better define the efficacy of SBRT in improving LC, PFS, and OS among patients with inoperable localized HCC. Prospective trials would overcome the current patient selection bias that increases the likelihood that patients with worse baseline liver function and performance will be treated with SBRT. The results of such a trial would further clarify the role of SBRT in the upfront management of these patients.

\section{Intermediate-Stage HCC}

Patients with BCLC stage-B HCC have large $(>3 \mathrm{~cm})$ tumors and/or multinodular tumors ( $>3$ foci) but have normal to moderately compromised liver function (CP A or B) [10]. Due to the increased tumor burden, BCLC stage- $\mathrm{B}$ HCC is not amenable to curative local therapy. Instead, these lesions are usually treated with arterial embolization techniques including transarterial embolization (TAE), transarterial chemoembolization (TACE), or transarterial radioembolization (TARE). These treatments exploit the preferential flow of blood from the hepatic artery to malignant lesions and the dual blood supply to the liver to infarct and potentially deliver cytotoxic chemotherapy or radiation beads to involved regions of the liver. This intervention is most appropriate for HCC that does not involve the main or lobar 
branch portal vein thrombus, as embolization of these lesions would significantly compromise global hepatic function. In carefully selected patients, prospective trials show arterial embolization is superior to supportive care only, but these interventions only achieved an objective response rate on imaging of 22-39\% at 6 months [21,59-61]. As a result, there has been increased interest in the use of SBRT with intermediate-risk disease to improve the rate of local control.

Retrospective and prospective studies have demonstrated that SBRT improves local control in patients with intermediate-stage HCC. A single-institution phase I/II trial at Korea Cancer Center Hospital analyzed 41 patients with HCC treated with SBRT after prior treatment TACE (up to 5 times) and demonstrated a 2-year local control of $94 \%$ and progression-free survival of $33.8 \%$ [48, 62]. The majority of failures were out-of-field hepatic tumors, which may represent additional candidate lesions for SBRT. Repeat radiation for additional liver lesions requires great caution to minimize hepatic toxicity [63-65] but can be done. A small retrospective of analysis of 24 patients who received an additional course of Cyberknife SBRT for a new hepatic lesion at least 6 months after the first treatment demonstrated SBRT 3-y OS of $60.8 \%$ and 3y local control of $90.7 \%$ [64].

In addition to demonstrating efficacy, these studies have shown that SBRT has a favorable side-effect profile compared with arterial embolization. In general, SBRT is well-tolerated, associated with mild acute fatigue, loss of appetite, and potentially nausea for lesions located near the stomach. Reported grade $\geq 3$ toxicity ranges from 5 to $30 \%$. Long-term effects can include GI bleeds in patients with tumors near the bowel, but that risk is in the single digits. Recent studies have established that repeat SBRT is also well-tolerated. Sun J et al. reported that the most common adverse effect was fatigue, and only one patient experienced radiation-induced liver disease (RILD). Notably, the majority of patients in this cohort had CP A disease, suggesting that selection for better baseline function may have contributed to limited adverse effects of re-irradiation. In contrast, arterially directive therapy has been associated with up to $10-80 \%$ acute grade 3 toxicity, particularly in patients with alcoholic cirrhosis and central lesions.

Despite the evidence that SBRT added to TACE improved local control, the role of adding TACE to SBRT remains unclear and a prospective comparison study is needed. A retrospective analysis of 209 patients at the University of Michigan aimed to clarify outcomes of SBRT compared with TACE for patients with 1-2 tumors. SBRT was associated with much higher local control (2-year LC of $91 \%$ vs. $23 \%$ ), though the SBRT cohort included slightly smaller lesions $(2.3 \mathrm{~cm}$ vs. $2.9 \mathrm{~cm}$ ). A recent meta-analysis suggests that SBRT combined with TACE compared SBRT alone is associated with higher 5 -year survival and complete response rate [66]. However, the meta-analysis consists of 10 small retrospective studies with heterogeneously classified study cohorts and high heterogeneity between the reported outcomes. Thus, the results should be interpreted with caution.

Additional prospective studies are needed to further define the timing and sequencing of SBRT in patients with intermediate-stage HCC. A randomized, prospective, openlabel, and phase II trial at the Erasmus Medical Center is investigating the efficacy of TACE versus SBRT and further clarifying the appropriate management for these patients. Other important questions include the efficacy of combination SBRT and TACE compared with individual therapies in treatment-naive patients, and the safety and efficacy of reirradiation for disease progression. For the combination of SBRT and TACE, additional data is needed to identify the ideal sequencing of the two interventions.

\section{Advanced-Stage HCC and Vascular Invasion}

BCLC stage-C HCC is defined by macroscopic vascular invasion, mild to moderate impairment of liver function or performance status, or extrahepatic extension $[10,11]$. Patients are at risk for decompensated cirrhosis, and portal hypertension due to portal venous thrombosis (PVT) is associated with worse overall survival $[11,49]$. Thus, it is generally treated with systemic therapy. Multiple randomized trials have established sorafenib as the standard of care agent that improved survival compared with placebo [67-69]. A recent trial phase III trial has demonstrated the superior efficacy of atezolizumab and bevacizumab in first-line medical management on unresectable hepatocellular carcinoma [70]. In addition to systemic therapy, select patients with portal venous thrombosis (PVT) may benefit from locoregional therapies.

SBRT can be an effective treatment for patients with impaired liver function and/or macroscopic vascular invasion. Without local therapy, patients with advanced HCC treated with sorafenib have a 1-year overall survival of $30-45 \%$ [68, 69]. An early phase I at Princess Margaret Hospital of 31 patients with unresectable $\mathrm{HCC}$ and $\mathrm{CP}$ A liver disease treated with 6-fraction SBRT demonstrated a median survival of 11.6 months for patients with PVT and 17.2 months without PVT [47]. Additional studies have shown that SBRT is effective in patients with poor baseline liver function. In a prospective study at Princess Margaret Hospital, 29 patients with Child-Pugh B7 or B8 liver function and $\mathrm{HCC}$ with $<5$ foci and total diameter $<10 \mathrm{~cm}$ treated with SBRT achieved a median survival of 7.9 , which compares favorably to the median survival of $\sim 4$ months in prior series $[58,71]$. A larger sequential phase I/II study evaluated the local control and survival in 102 patients who received SBRT for advanced HCC [49]. Over $60 \%$ of patients had multiple lesions, $55 \%$ of tumors were associated with tumor invasion of a major vessel, and the median diameter of the largest lesions was $7.7 \mathrm{~cm}$. Treatment with SBRT was associated with a 1-year 
local control of $87 \%$, and radiation dose predicted improved local control on univariate analysis.

\section{How Does Radiation Therapy Compare with Other Local and Systemic Therapy Interventions for Patients with PVT?}

A meta-analysis pooled the data from prospective and retrospective studies of 2513 patients who received 3D CRT, transarterial radioembolization (TARE), or SBRT for HCC with PVT to analyze overall survival, response rate, local control, and toxicity [72]. The 1-year overall survival for the three modalities was similar ( 44-48\%). Notably, the local control rate associated with SBRT (86.9\%) and 3D CRT (82.8\%) was higher than TARE (57.5\%), and the overall response rate was higher from SBRT $(70.7 \%)$ than 3D CRT $(51.3 \%)$ or TARE (33.3\%). SBRT also improved patient symptoms. More than two-thirds of the patients treated with SBRT experienced improved abdominal distention and/or discomfort. A recent randomized trial compared local therapy with TACE and 3D CRT versus sorafenib in treatment-naive patients with liverconfined HCC with macroscopic vascular invasion [73]. Patients treated with TACE-RT had a significantly higher radiologic response rate $(15 \%$ vs. $1 \%)$ at 24 weeks and progression-free survival $(86.7 \%$ vs. $34.3 \%)$ at 12 weeks and a longer median overall survival (55 vs. 43 weeks) and time to progress ( 31 vs. 11.7 weeks). To date, no randomized control trials are comparing SBRT monotherapy to other local or systemic interventions for patients with advanced HCC with PVT. However, the pooled analysis shows that SBRT offers improved local control and progression-free survival, and the recent randomized trial demonstrates that local therapy options offer effective treatment in carefully selected patients with advanced liver-confined HCC with portal venous thrombosis.

Despite the increased risk of hepatic decompensation and poor functional status of patients with advanced-stage HCC, SBRT is generally well-tolerated. The meta-analysis of retrospective and prospective studies reported a grade 3 or higher toxicity of 0 to $10 \%$ [72]. Other prospective studies reported grade 3 or higher toxicity of 26 to $36 \%$ [47, 49, 51, 58]. The most common severe adverse effects included transaminitis and liver failure, and in one trial, the percentage of patients experiencing liver deterioration in the absence of tumor progression after 1 year was $6 \%$ for CP class and $17 \%$ of CP score. Notably, $11 \%$ of patients in the sorafenib group required dose reduction due to toxicity while no patients required dose reduction in the TACE-RT group.

Additional studies are needed to further define the appropriate treatment for patients with advanced HCC. Randomized trials are needed to validate the efficacy and safety of SBRT compared with other local therapy modalities. In addition, future studies should aim to clarify the ideal combination of RT, arterial embolization, and/or systemic therapy that improves disease control and overall survival while minimizing toxicity [74]. After all, the studies presented herein suggest that carefully selected patients with BCLC patients may be effectively managed with local therapy with delay or omission of systemic therapy. Three randomized trials of patients with advanced HCC have already reported no survival benefit from sorafenib alone compared with TARE with or without sorafenib $[28,75,76]$. Additional studies to clarify the selection between local and systemic therapy options are particularly important in light of recent studies demonstrating improved disease control and survival with immunotherapy [70]. Currently, there are several ongoing randomized trials investigating sorafenib with or without TACE (NCT01829035 and NCT01906216) or sorafenib with or without SBRT (NCT0173093 and RTOG 1112). Recent advances in the systemic therapy options will require careful analysis of these study results to determine the role of local therapy as firstline systemic therapy options evolve.

\section{Patient Experience}

It is also important to understand patients' experiences with receiving SBRT. Treatment planning begins with a 1-h simulation consisting of a CT scan with intravenous contrast of the liver in the treatment position. Patients lie flat with their hands above their heads or at their sides and behind their bodies, depending on the treatment machine. Several techniques including breath-hold, respiratory gating, and fiducial tracking may be used to control for tumor motion during the respiratory cycle to minimize the rim of the normal liver that receives radiation. Planning typically takes 1.5 weeks due to its complexity and requirement for many quality assurance steps. Treatment usually requires patients to lie still in the treatment position for 20 to $60 \mathrm{~min}$. Patients usually receive 3 to 5 sessions of treatment over 1-1.5 weeks. These treatments are conducted as an outpatient and do not require hospitalization or anesthesia. Most patients drive themselves to treatment and tolerate the treatment very well, even coming for treatment during their lunch break from work. While on treatment, patients are monitored weekly for acute toxicity, which could include mild nausea for tumors near the stomach. Quality of life has been studied during and after treatment and is minimally impacted $[77,78]$.

\section{Post-SBRT Monitoring}

What is the anticipated course after SBRT? Monitoring patients after SBRT is critical for assessing disease response and the need for additional treatment, particularly since patients can develop new lesions within the liver due to the field cancerization effect. The post-treatment disease control depends on the baseline performance status, tumor size, biological markers, and liver function. Better baseline liver function 
(CP A vs. CP B and C), lower albumin-bilirubin index (ALBI), and lower pretreatment AFP are associated with better survival and fewer acute and late grade 2 toxicity after SBRT [79]. Smaller tumors are associated with increased radiographic response to SBRT, decreased disease progression, and overall survival.

Assessing patient response to SBRT is challenging and requires a radiologist familiar with both $\mathrm{HCC}$ and postradiation imaging. A handful of radiology-pathology correlation studies in the transplant setting have been useful to characterize imaging changes in response to therapy. As opposed to a treatment like RFA or TACE, in which response (complete necrosis) can be judged at the 4-6-week mark, patience is required to appreciate a radiation response (Fig. 1). Generally, early follow-up (3-6 months) can show a zone of hyperemia including and surrounding the tumor on the arterial phase, related to edema from treatment. This will improve up to 12 months, with decreased tumor enhancement and size. Explant pathologic studies have shown that persistent enhancement does not mean that tumors are still viable, so there is no need to jump in with additional treatment unless the AFP is rising [80-82]. Portal venous washout can persist up to 12 months after treatment as well, improving over time [30, $39,41,80,83,84]$. The zone of washout can increase, due to changes in the function of liver parenchyma around the tumor, reflecting the high dose radiation zone. Thus, the typical metric for response is a lack of progression or local control [85, 86]. Scans will continue to improve for 6-12 months, and AFP will reassuringly also fall [28, 70, 75, 76]. However, these findings can persist for more than 1 year in up to $1 / 3$ of patients, and it is important to ensure that they are distinguished from local recurrence or progression, to avoid subjecting patients to unnecessary subsequent treatments.

In addition to monitoring for disease response, patients require surveillance for toxicity. Although the treatment is generally well-tolerated, one of the most severe adverse effects includes RILD. It manifests as anicteric hepatomegaly, ascites, and elevated liver enzymes (i.e., ALP >> ALT and
AST) about 2 weeks to 3 months after SBRT. Delaying liver MRI to 3 to 6 months after treatment can help ensure sufficient time for normal parenchyma recovery and adequately diagnosed RILD [87, 88]. Compared with conventional radiation performed decades ago, the risk of RILD is decreased with SBRT limiting radiation dose to the normal parenchyma [89-91]. A recent release nomogram may help predict the risk of post-treatment radiation-induced hepatitis [92]. Additional adverse effects that require monitoring include GI toxicity (gastric and duodenal ulcers or perforation), although the incidence is quite rare [93, 94].

\section{Conclusion}

This review synthesized current data on the indications, patient selection, outcomes, and post-treatment monitoring of SBRT. The data show that SBRT is a safe and effective treatment for patients who are not candidates for definitive surgical management. Retrospective and prospective series have shown that SBRT can effectively bridge patients to transplantation and achieves excellent local control in patients with early-stage inoperable, intermediate stage, and advanced disease. Unlike other local treatment modalities, SBRT is appropriate for patients with unfavorable locations (e.g., adjacent to the heart, bowel, or central biliary structures; or invading large vessels). Emerging data demonstrate that it is safe to provide repeat radiation for patients who have intrahepatic progression, either to the same lesion or a new one, with proper consideration of remnant liver function. Although patients who receive SBRT often have worse baseline performance status compared with other local therapy modalities, SBRT is well-tolerated and associated with few grade $\geq 3$ toxicities compared with other local therapy options. Prospective trials of SBRT in comparison with and combination with other local and systemic therapies are needed to clarify the optimal role of SBRT for patients with HCC.
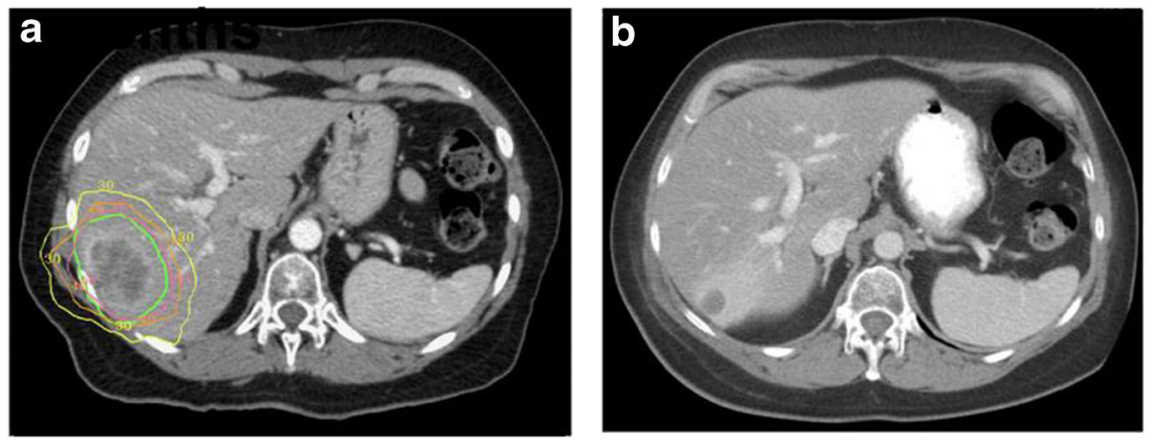

Fig. 1 Axial CT scans of the abdomen with contrast depicting stereotactic body radiation therapy (SBRT) to a solitary hepatocellular carcinoma (a) and the radiographic evolution of the lesion at 3 months (b) and

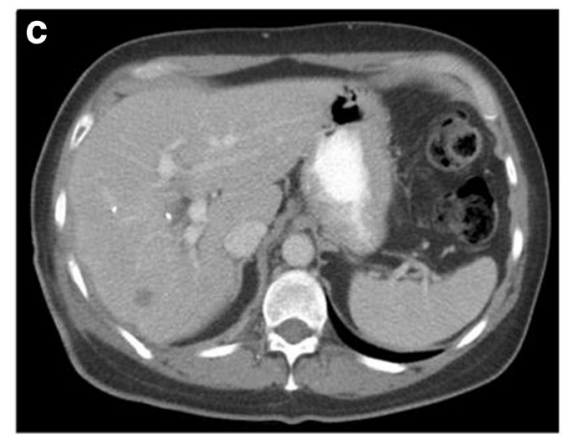

15 months (c) after treatment. The radiation dose gradient is represented by the colored lines in $\mathbf{a}$. Red $=50 \mathrm{~Gy}$ (prescription dose). Orange = 40 Gy. Yellow $=30$ Gy 


\section{Compliance with Ethical Standards}

Conflict of Interest The authors declare that they have no conflict of interest.

Human and Animal Rights and Informed Consent This article does not contain any studies with human or animal subjects performed by any of the authors.

Open Access This article is licensed under a Creative Commons Attribution 4.0 International License, which permits use, sharing, adaptation, distribution and reproduction in any medium or format, as long as you give appropriate credit to the original author(s) and the source, provide a link to the Creative Commons licence, and indicate if changes were made. The images or other third party material in this article are included in the article's Creative Commons licence, unless indicated otherwise in a credit line to the material. If material is not included in the article's Creative Commons licence and your intended use is not permitted by statutory regulation or exceeds the permitted use, you will need to obtain permission directly from the copyright holder. To view a copy of this licence, visit http://creativecommons.org/licenses/by/4.0/.

\section{References}

Papers of particular interest, published recently, have been highlighted as:

- Of importance

1. Bray F, Ferlay J, Soerjomataram I, Siegel RL, Torre LA, Jemal A. Global cancer statistics 2018: GLOBOCAN estimates of incidence and mortality worldwide for 36 cancers in 185 countries. CA Cancer J Clin. 2018;68:394-424.

2. Wong MCS, Jiang JY, Goggins WB, Liang M, Fang Y, Fung FDH, et al. International incidence and mortality trends of liver cancer: a global profile. Sci Rep. 2017;7:45846.

3. Jemal A, Bray F, Center MM, Ferlay J, Ward E, Forman D. Global cancer statistics. CA Cancer J Clin. 2011;61:69-90.

4. Altekruse SF, McGlynn KA, Reichman ME. Hepatocellular carcinoma incidence, mortality, and survival trends in the United States from 1975 to 2005. J Clin Oncol Off J Am Soc Clin Oncol. 2009;27:1485-91.

5. Bosetti C, Levi F, Boffetta P, Lucchini F, Negri E, Vecchia CL. Trends in mortality from hepatocellular carcinoma in Europe, 19802004. Hepatol Baltim Md. 2008;48:137-45.

6. Baecker A, Liu X, Vecchia C, Zhang Z. Worldwide incidence of hepatocellular carcinoma cases attributable to major risk factors. Eur J Cancer Prev. 2018;27:205-12.

7. Marengo A, Rosso C, Bugianesi E. Liver cancer: connections with obesity, fatty liver, and cirrhosis. Annu Rev Med. 2015;67:103-17.

8. Investigators Tc. A new prognostic system for hepatocellular carcinoma: a retrospective study of 435 patients. Hepatology. 1998;28: $751-5$.

9. Okuda K, Ohtsuki T, Obata H, Tomimatsu M, Okazaki N, Hasegawa $\mathrm{H}$, et al. Natural history of hepatocellular carcinoma and prognosis in relation to treatment study of 850 patients. Cancer. 1985;56:918-28.

10. Llovet J, Brú C, Bruix J. Prognosis of hepatocellular carcinoma: The BCLC staging classification. Semin Liver Dis. 1999;19:329_ 38 .
11. Izumi R, Shimizu KT II, Yagi M, Matsui O, Nonomura A, et al. Prognostic factors of hepatocellular carcinoma in patients undergoing hepatic resection. Gastroenterology. 1994;106:720-7.

12. Kudo M, Chung H, Osaki Y. Prognostic staging system for hepatocellular carcinoma (CLIP score): its value and limitations, and a proposal for a new staging system, the Japan Integrated Staging Score (JIS score). J Gastroenterol. 2003;38:207-15.

13. Burkhart R, Pawlik T. Staging and prognostic models for hepatocellular carcinoma and intrahepatic cholangiocarcinoma. Cancer Control. 2017;24:1073274817729235.

14. Benson AB, Abrams TA, Ben-Josef E, Bloomston PM, Botha JF, Clary BM, et al. Hepatobiliary cancers. J Natl Compr Canc Netw. 2009;7:350-91.

15. Benson AB, D'Angelica MI, Abbott DE, Abrams TA, Alberts SR, Anaya DA, et al. NCCN Guidelines insights: hepatobiliary cancers, Version 1.2017. J Natl Compr Canc Netw. 2017;15:563-73.

16. Higuchi Y, Serizawa T, Nagano O, Matsuda S, Ono J, Sato M, et al. Three-staged stereotactic radiotherapy without whole brain irradiation for large metastatic brain tumors. Int J Radiat Oncol. 2009;74: 1543-8.

17. Llovet JM. Updated treatment approach to hepatocellular carcinoma. J Gastroenterol. 2005;40:225-35.

18. Heckman JT, deVera MB, Marsh JW, Fontes P, Amesur NB, Holloway SE, et al. Bridging locoregional therapy for hepatocellular carcinoma prior to liver transplantation. Ann Surg Oncol. 2008;15:3169-77.

19. Pang T, Lam V. Surgical management of hepatocellular carcinoma. World J Hepatol. 2014;7:245.

20. Chen X, Liu H, Li M, Qiao L. Advances in non-surgical management of primary liver cancer. World J Gastroenterol. 2014;20: 16630.

21. Llovet JM, Real MI, Montaña X, Planas R, Coll S, Aponte J, et al. Arterial embolisation or chemoembolisation versus symptomatic treatment in patients with unresectable hepatocellular carcinoma: a randomised controlled trial. The Lancet. 2002;359:1734-9.

22. Park W, Lim DH, Paik SW, Koh KC, Choi MS, Park CK, et al. Local radiotherapy for patients with unresectable hepatocellular carcinoma. Int J Radiat Oncol. 2005;61:1143-50.

23. Cunningham SC, Tsai S, Marques HP, Mira P, Cameron A, Barroso E, et al. Management of early hepatocellular carcinoma in patients with well-compensated cirrhosis. Ann Surg Oncol. 2009;16:1820-31.

24. Liver EA for the S of the, Galle PR, Forner A, Llovet JM, Mazzaferro V, Piscaglia F, et al. EASL clinical practice guidelines: management of hepatocellular carcinoma. J Hepatol. 2018;69:182236.

25. Shah SA, Cleary SP, Tan JCC, Wei AC, Gallinger S, Grant DR, et al. An Analysis of resection vs transplantation for early hepatocellular carcinoma: defining the optimal therapy at a single institution. Ann Surg Oncol. 2007;14:2608-14.

26. Freeman RB, Edwards EB, Harper AM. Waiting list removal rates among patients with chronic and malignant liver diseases. Am J Transplant. 2006;6:1416-21.

27. Huang J, Yan L, Cheng Z, Wu H, Du L, Wang J, et al. A randomized trial comparing radiofrequency ablation and surgical resection for HCC conforming to the Milan Criteria. Ann Surg. 2010;252: 903-12.

28. Chow PKH, Gandhi M, Tan S-B, Khin MW, Khasbazar A, Ong J, et al. SIRveNIB: selective internal radiation therapy versus sorafenib in Asia-Pacific patients with hepatocellular carcinoma. J Clin Oncol. 2018;36:1913-21.

29. Mazzaferro V, Citterio D, Bhoori S, Bongini M, Miceli R, Carlis $\mathrm{LD}$, et al. Liver transplantation in hepatocellular carcinoma after tumour downstaging (XXL): a randomised, controlled, phase $2 \mathrm{~b} / 3$ trial. Lancet Oncol. 2020;21:947-56. 
30. O'Connor J, Trotter J, Davis G, Dempster J, Klintmalm G, Goldstein R. Long-term outcomes of stereotactic body radiation therapy in the treatment of hepatocellular cancer as a bridge to transplantation. Liver Transpl. 2012;18:949-54.

31. Sandroussi C, Dawson LA, Lee M, Guindi M, Fischer S, Ghanekar $\mathrm{A}$, et al. Radiotherapy as a bridge to liver transplantation for hepatocellular carcinoma. Transpl Int. 2010;23:299-306.

32. Mannina EM, Cardenes HR, Lasley FD, Goodman B, Zook J, Althouse S, et al. Role of stereotactic body radiation therapy before orthotopic liver transplantation: retrospective evaluation of pathologic response and outcomes. Int J Radiat Oncol Biol Phys. 2017;97:931-8.

33. Mazloom A, Hezel AF, Katz AW. Stereotactic body radiation therapy as a bridge to transplantation and for recurrent disease in the transplanted liver of a patient with hepatocellular carcinoma. Case Rep Oncol. 2014;7:18-22.

34. Mornex F, Girard N, Beziat C, Kubas A, Khodri M, Trepo C, et al. Feasibility and efficacy of high-dose three-dimensional-conformal radiotherapy in cirrhotic patients with small-size hepatocellular carcinoma non-eligible for curative therapies - mature results of the French Phase II RTF-1 trial. Int J Radiat Oncol. 2006;66:1152-8.

35. Ben-Josef E, Normolle D, Ensminger WD, Walker S, Tatro D, Haken RKT, et al. Phase II trial of high-dose conformal radiation therapy with concurrent hepatic artery floxuridine for unresectable intrahepatic malignancies. J Clin Oncol. 2005;23:8739-47.

36. Andolino D, Johnson C, Maluccio M, Kwo P, Tector A, Zook J, et al. Stereotactic body radiotherapy for primary hepatocellular carcinoma. Int J Radiat Oncol. 2011;81:e447-53.

37. Sapisochin G, Barry A, Doherty M, Fischer S, Goldaracena N, Rosales R, et al. Stereotactic body radiotherapy vs. TACE or RFA as a bridge to transplant in patients with hepatocellular carcinoma. An intention-to-treat analysis. J Hepatol. 2017;67:92-9 This study compared outcomes of patients treated with TACE, RFA, and SBRT when used as a bridge to transplant. There were no differences in overall survival, transplant rate, or postoperative complications between groups.

38. Moore A, Cohen-Naftaly M, Tobar A, Kundel Y, Benjaminov O, Braun M, et al. Stereotactic body radiation therapy (SBRT) for definitive treatment and as a bridge to liver transplantation in early stage inoperable Hepatocellular carcinoma. Radiat Oncol. 2017;12: 163.

39. Facciuto M, Singh M, Rochon C, Sharma J, Gimenez C, Katta U, et al. Stereotactic body radiation therapy in hepatocellular carcinoma and cirrhosis: Evaluation of radiological and pathological response. J Surg Oncol. 2012;105:692-8.

40. Guarneri A, Franco P, Romagnoli R, Trino E, Mirabella S, Molinaro L, et al. Stereotactic ablative radiation therapy prior to liver transplantation in hepatocellular carcinoma. Radiol Med (Torino). 2016;121:873-81.

41. Katz A, Chawla S, Qu Z, Kashyap R, Milano M, Hezel A. Stereotactic hypofractionated radiation therapy as a bridge to transplantation for hepatocellular carcinoma: clinical outcome and pathologic correlation. Int J Radiat Oncol. 2012;83:895-900.

42. Nugent FW, Gunturu K, Stuart KE, Flacke S, Molgaard C, Hunter $\mathrm{K}$, et al. A randomized phase II study of individualized stereotactic body radiation therapy (SBRT) versus transarterial chemoembolization (TACE) as a bridge to transplant in hepatocellular carcinoma (HCC). J Clin Oncol. 2017;35:e15677.

43. Parikh N, Waljee A, Singal A. Downstaging hepatocellular carcinoma: a systematic review and pooled analysis. Liver Transpl. 2015;21:1142-52.

44. Weis S, Franke A, Mössner J, Jakobsen JC, Schoppmeyer K. Radiofrequency (thermal) ablation versus no intervention or other interventions for hepatocellular carcinoma. Cochrane Database Syst Rev. 2013;12:CD003046.
45. Romero AM, Wunderink W, Hussain SM, Pooter JAD, Heijmen BJM, Nowak PCJM, et al. Stereotactic body radiation therapy for primary and metastatic liver tumors: a single institution phase i-ii study. Acta Oncol. 2009;45:831-7.

46. Lasley FD, Mannina EM, Johnson CS, Perkins SM, Althouse S, Maluccio M, et al. Treatment variables related to liver toxicity in patients with hepatocellular carcinoma, Child-Pugh class A and B enrolled in a phase 1-2 trial of stereotactic body radiation therapy. Pract Radiat Oncol. 2015;5:e443-9.

47. Tse RV, Hawkins M, Lockwood G, Kim JJ, Cummings B, Knox J, et al. Phase I study of individualized stereotactic body radiotherapy for hepatocellular carcinoma and intrahepatic cholangiocarcinoma. J Clin Oncol Off J Am Soc Clin Oncol. 2008;26:657-64.

48. Kang J, Kim M, Cho CK, Yang KM, Yoo HJ, Kim JH, et al. Stereotactic body radiation therapy for inoperable hepatocellular carcinoma as a local salvage treatment after incomplete transarterial chemoembolization. Cancer. 2012;118:5424-31.

49. Bujold A, Massey CA, Kim JJ, Brierley J, Cho C, Wong RKS, et al. Sequential phase I and II trials of stereotactic body radiotherapy for locally advanced hepatocellular carcinoma. J Clin Oncol. 2013;31: 1631-9.

50. Takeda A, Sanuki N, Tsurugai Y, Iwabuchi S, Matsunaga K, Ebinuma H, et al. Phase 2 study of stereotactic body radiotherapy and optional transarterial chemoembolization for solitary hepatocellular carcinoma not amenable to resection and radiofrequency ablation. Cancer. 2016;122:2041-9.

51. Feng M, Suresh K, Schipper MJ, Bazzi L, Ben-Josef E, Matuszak $\mathrm{MM}$, et al. Individualized adaptive stereotactic body radiotherapy for liver tumors in patients at high risk for liver damage: a phase 2 clinical trial. JAMA Oncol. 2017;4:40.

52. Jang WI, Bae SH, Kim M, Han CJ, Park SC, Kim SB, et al. A phase 2 multicenter study of stereotactic body radiotherapy for hepatocellular carcinoma: safety and efficacy. Cancer. 2019;126:363-72.

53. Durand-Labrunie J, Baumann A-S, Ayav A, Laurent V, Boleslawski E, Cattan S, et al. Curative irradiation treatment of hepatocellular carcinoma: a multicenter phase 2 Trial. Int J Radiat Oncol Biol Phys. 2020;107:116-25.

54. Wahl DR, Stenmark MH, Tao Y, Pollom EL, Caoili EM, Lawrence TS, et al. Outcomes after stereotactic body radiotherapy or radiofrequency ablation for hepatocellular carcinoma. J Clin Oncol. 2016;34:452-9.

55. Kimura T, Aikata H, Takahashi S, Takahashi I, Nishibuchi I, Doi Y, et al. Stereotactic body radiotherapy for patients with small hepatocellular carcinoma ineligible for resection or ablation therapies. Hepatol Res. 2015;45:378-86.

56. Méndez Romero A, Wunderink W, Hussain SM, De Pooter JA, Heijmen BJM, Nowak PCJM, et al. Stereotactic body radiation therapy for primary and metastatic liver tumors: a single institution phase i-ii study. Acta Oncol Stockh Swed. 2006;45:831-7.

57. Kubo K, Kimura T, Aikata H, Takahashi S, Takeuchi Y, Takahashi I, et al. Long-term outcome of stereotactic body radiotherapy for patients with small hepatocellular carcinoma. Hepatol Res Off J Jpn Soc Hepatol. 2018;48:701-7.

58. Culleton S, Jiang H, Haddad CR, Kim J, Brierley J, Brade A, et al. Outcomes following definitive stereotactic body radiotherapy for patients with Child-Pugh B or C hepatocellular carcinoma. Radiother Oncol. 2014;111:412-7.

59. Meyer T, Kirkwood A, Roughton M, Beare S, Tsochatzis E, Yu D, et al. A randomised phase II/III trial of 3-weekly cisplatin-based sequential transarterial chemoembolisation vs embolisation alone for hepatocellular carcinoma. Br J Cancer. 2013;108:1252-9.

60. Lo C, Ngan H, Tso W, Liu C, Lam C, Poon RT, et al. Randomized controlled trial of transarterial lipiodol chemoembolization for unresectable hepatocellular carcinoma. Hepatology. 2002;35: $1164-71$. 
61. Brown KT, Do RK, Gonen M, Covey AM, Getrajdman GI, Sofocleous CT, et al. Randomized trial of hepatic artery embolization for hepatocellular carcinoma using doxorubicin-eluting microspheres compared with embolization with microspheres alone. J Clin Oncol. 2016;34:2046-53.

62. Li D, Kang J, Madoff DC. Locally ablative therapies for primary and metastatic liver cancer. Expert Rev Anticancer Ther. 2014;14: 931-45.

63. Kimura T, Takeda A, Tsurugai Y, Kawano R, Doi Y, Oku Y, et al. A multi-institutional retrospective study of repeated stereotactic body radiation therapy for intra-hepatic recurrent hepatocellular carcinoma. Int J Radiat Oncol. 2020;108:1265-75.

64. Sun J, Ouyang C, Chang X, Zhang A, Wang Q, Li W, et al. Repeated CyberKnife stereotactic body radiation therapy in hepatocellular carcinoma. Radiat Oncol Lond Engl. 2020;15:10.

65. Gkika E, Strouthos I, Kirste S, Adebahr S, Schultheiss M, Bettinger $D$, et al. Repeated SBRT for in- and out-of-field recurrences in the liver. Strahlenther Onkol Organ Dtsch Rontgengesellschaft Al. 2018; 195:246-53.

66. Zhao J, Zeng L, Wu Q, Wang L, Lei J, Luo H, et al. Stereotactic body radiotherapy combined with transcatheter arterial chemoembolization versus stereotactic body radiotherapy alone as the first-line treatment for unresectable hepatocellular carcinoma: a meta-analysis and systematic review. Chemotherapy. 2020;64:111.

67. Bruix J, Raoul J-L, Sherman M, Mazzaferro V, Bolondi L, Craxi A, et al. Efficacy and safety of sorafenib in patients with advanced hepatocellular carcinoma: subanalyses of a phase III trial. J Hepatol. 2012;57:821-9.

68. Cheng A-L, Kang Y-K, Chen Z, Tsao C-J, Qin S, Kim JS, et al. Efficacy and safety of sorafenib in patients in the Asia-Pacific region with advanced hepatocellular carcinoma: a phase III randomised, double-blind, placebo-controlled trial. Lancet Oncol. 2009; 10:25-34.

69. Llovet JM, Ricci S, Mazzaferro V, Hilgard P, Gane E, Blanc J-F, et al. Sorafenib in advanced hepatocellular carcinoma. N Engl J Med. 2008;359:378-90.

70. Finn RS, Qin S, Ikeda M, Galle PR, Ducreux M, Kim T-Y, et al. Atezolizumab plus bevacizumab in unresectable hepatocellular carcinoma. N Engl J Med. 2020;382:1894-905.

71. Hollebecque A, Cattan S, Romano O, Sergent G, Mourad A, Louvet A, et al. Safety and efficacy of sorafenib in hepatocellular carcinoma: the impact of the Child-Pugh score: sorafenib in ChildPugh B patients with advanced HCC. Aliment Pharmacol Ther. 2011;34:1193-201.

72. Rim CH, Kim CY, Yang DS, Yoon WS. Comparison of radiation therapy modalities for hepatocellular carcinoma with portal vein thrombosis: a meta-analysis and systematic review. Radiother Oncol. 2018;129:112-22.

73. Yoon SM, Ryoo B-Y, Lee SJ, Kim JH, Shin JH, An JH, et al. Efficacy and safety of transarterial chemoembolization plus external beam radiotherapy vs sorafenib in hepatocellular carcinoma with macroscopic vascular invasion. JAMA Oncol. 2018;4:661.

74. Sebastian NT, Miller ED, Yang X, Diaz DA, Tan Y, Dowell J, et al. A pilot trial evaluating stereotactic body radiation therapy to induce hyperemia in combination with transarterial chemoembolization for hepatocellular carcinoma. Int J Radiat Oncol. 2020;

75. Vilgrain V, Pereira H, Assenat E, Guiu B, Ilonca AD, Pageaux G-P, et al. Efficacy and safety of selective internal radiotherapy with yttrium-90 resin microspheres compared with sorafenib in locally advanced and inoperable hepatocellular carcinoma (SARAH): an open-label randomised controlled phase 3 trial. Lancet Oncol. 2017;18:1624-36.

76. Ricke J, Klümpen HJ, Amthauer H, Bargellini I, Bartenstein P, de TEN, et al. Impact of combined selective internal radiation therapy and sorafenib on survival in advanced hepatocellular carcinoma. J Hepatol. 2019;71:1164-74.

77. Klein J, Dawson LA, Jiang H, Kim J, Dinniwell R, Brierley J, et al. Prospective longitudinal assessment of quality of life for liver cancer patients treated with stereotactic body radiation therapy. Int $\mathrm{J}$ Radiat Oncol. 2015;93:16-25.

78. Mutsaers A, Greenspoon J, Walker-Dilks C, Swaminath A. Systematic review of patient reported quality of life following stereotactic ablative radiotherapy for primary and metastatic liver cancer. Radiat Oncol. 2017;12:110.

79. Gkika E, Schultheiss M, Bettinger D, Maruschke L, Neeff H, Schulenburg M, et al. Excellent local control and tolerance profile after stereotactic body radiotherapy of advanced hepatocellular carcinoma. Radiat Oncol. 2017;12:116.

80. Olsen C, Welsh J, Kavanagh B, Franklin W, McCarter M, Cardenes $\mathrm{H}$, et al. Microscopic and macroscopic tumor and parenchymal effects of liver stereotactic body radiotherapy. Int J Radiat Oncol. 2009;73:1414-24.

81. Ingold JA, Reed GB, Kaplan HS, Bagshaw MA. Radiation hepatitis. Am J Roentgenol Radium Ther Nucl Med. 1965;93:200-8.

82. Reed GB, Cox AJ. The human liver after radiation injury. A form of veno-occlusive disease. Am J Pathol. 1966;48:597-611.

83. Herfarth KK, Hof H, Bahner ML, Lohr F, Höss A, van KG, et al. Assessment of focal liver reaction by multiphasic CT after stereotactic single-dose radiotherapy of liver tumors. Int J Radiat Oncol. 2003;57:444-51.

84. Takeda A, Oku Y, Sanuki N, Kunieda E, Koike N, Aoki Y, et al. Dose volume histogram analysis of focal liver reaction in follow-up multiphasic CT following stereotactic body radiotherapy for small hepatocellular carcinoma. Radiother Oncol. 2012;104:374-8.

85. Mendiratta-Lala M, Gu E, Owen D, Cuneo KC, Bazzi L, Lawrence TS, et al. Imaging findings within the first 12 months of hepatocellular carcinoma treated with stereotactic body radiation therapy. Int J Radiat Oncol Biol Phys. 2017;102:1063-9.

86. Haddad M, Merrell K, Hallemeier C, Johnson G, Mounajjed T, Olivier K, et al. Stereotactic body radiation therapy of liver tumors: post-treatment appearances and evaluation of treatment response: a pictorial review. Abdom Radiol. 2016;41:2061-77.

87. Sanuki N, Takeda A, Oku Y, Eriguchi T, Nishimura S, Aoki Y, et al. Threshold doses for focal liver reaction after stereotactic ablative body radiation therapy for small hepatocellular carcinoma depend on liver function: evaluation on magnetic resonance imaging with Gd-EOB-DTPA. Int J Radiat Oncol. 2014;88:306-11.

88. Sanuki N, Takeda A, Oku Y, Eriguchi T, Nishimura S, Aoki Y, et al. Influence of liver toxicities on prognosis after stereotactic body radiation therapy for hepatocellular carcinoma: Liver toxicities after SBRT for HCC. Hepatol Res. 2014;45:540-7.

89. Bentzen SM, Constine LS, Deasy JO, Eisbruch A, Jackson A, Marks LB, et al. Quantitative analyses of normal tissue effects in the clinic (QUANTEC): an introduction to the scientific issues. Int J Radiat Oncol. 2010;76:S3-9.

90. Doi H, Shiomi H, Masai N, Tatsumi D, Igura T, Imai Y, et al. Threshold doses and prediction of visually apparent liver dysfunction after stereotactic body radiation therapy in cirrhotic and normal livers using magnetic resonance imaging. J Radiat Res (Tokyo). 2016;57:294-300. 
91. Emami B, Lyman J, Brown A, Coia L, Goitein M, Munzenrider JE, et al. Tolerance of normal tissue to therapeutic irradiation. Radiat Oncol Biol. 1991;21:109-22.

92. Su T-S, Luo R, Liang P, Cheng T, Zhou Y, Huang Y. A prospective cohort study of hepatic toxicity after stereotactic body radiation therapy for hepatocellular carcinoma. Radiother Oncol. 2018;129: 136-42.

93. Bae SH, Kim M-S, Cho CK, Kim KB, Lee DH, Han CJ, et al. Feasibility and efficacy of stereotactic ablative radiotherapy for
Barcelona Clinic Liver Cancer-C stage hepatocellular carcinoma. J Korean Med Sci. 2013;28:213-9.

94. Huang W-Y, Jen Y-M, Lee M-S, Chang L-P, Chen C-M, Ko K-H, et al. Stereotactic body radiation therapy in recurrent hepatocellular carcinoma. Int J Radiat Oncol. 2012;84:355-61.

Publisher's Note Springer Nature remains neutral with regard to jurisdictional claims in published maps and institutional affiliations. 